\title{
Evaluation of Aircraft Interior Panels under Full-scale Cabin Fire Test Conditions
}

CONSTANTINE P. SARKOS and RICHARD G. HILL

Federal Aviation Administration

FAA Technical Center

Atlantic City Airport: New Jersey 08405, USA

\section{ABSTRACT}

Realistic ful1-scale fire tests demonstrated the potential safety benefits of advanced interior panels in transport aircraft, and displayed the characteristics of cabin fire hazards. The tests were conducted in a C-133 airplane, modified to resemble a wide-body interior, under postcrash and in-flight fire scenarios. The safety benefit of the advanced panel ranged from a 2-minute delay in the onset of flashover when the cabin fire was initiated by a fuel fire adjacent to a fuselage rupture, to the elimination of flashover when the fuel fire was adjacent to a door opening or when an in-flight fire was started from a seat drenched in gasoline. Analysis of the cabin hazards measured during postcrash fire tests indicated that the greatest threat to passenger survival was cabin $\mathrm{fl}$ ashover, and that toxic gases did not reach hazardous levels unless flashover occurred.

\section{INTRODUCTION}

objective

The primary objective of this paper is to describe the safety benefits of advanced interior panels under realistic full-scale aircraft cabin fire test conditions. A secondary objective is to characterize and analyze the hazards affecting occupant survivability in cabin fires.

Background

Although the accident record of the airline industry is excellent, on rare occasions accidents do occur with grave consequences. For the United States (U.S.) airline industry, an average of 32 fatalities per year are attributable to fire. 1 A11 of these fatalities have occurred in crash accidents which are usually accompanied by the spillage and ignition of jet fuel. In spite of the intensity and apparent dominance of a jet fuel fire, under certain accident conditions, the survivability of cabin occupants will be established by the hazards of burnin interior materials. 2 The Federal Aviation Administration (FAA) is supporting and conducting research, testing and development to minimize the hazards of burning interior materials in the postcrash fire environment. 3 Also, the in-flight fire problem is now receiving more 
attention because of this type of accident experience with foreign carriers; e.g., Air Canada DC9 accident in Cincinnati.

Improvements for two important types of cabin interior materials have been investigated - seat cushions and panels. Because of the flammable nature of urethane foam cushions, a fire blocking layer concept was developed that provides significant safety benefits for both postcrash and in-flight cabin fires. 5 The FAA has proposed more stringent flammability regulations for seat cushions. 6 The current emphas is by FAA is to develop improved test requirements and materials for interior panels, which constitute the sidewalls, ceiling, stowage bins, and partitions of a contemporary transport cabin interior. The importance of panels during a cabin fire stems from their large surface area and location in the upper cabin (ceiling, stowage bins) where fire temperatures are highest.

Ful1-scale fire tests are necessary to determine the potential benefits of safety improvements in real fires and to corroborate the trends indicated by small-scale test results. During full-scale tests, important real-world conditions such as fire source, geometry, and scale are reasonably simulated. Another important application of ful1-scale fire tests, is for the analysis of the hazards affecting survivability during a cabin fire. These hazards are grouped into three categories: heat, smoke (visibility), and toxic gases. What is the relative importance of each of these hazards? What are the effects of different types of fire scenarios on the significance of each hazard category? Realistic full-scale tests can provide information which, at the very least, give insight for answering these complex and far-reaching questions.

\section{DISCUSSION}

Interior Panel Materials

Figure 1 describes the advanced and inservice panels evaluated in this paper.

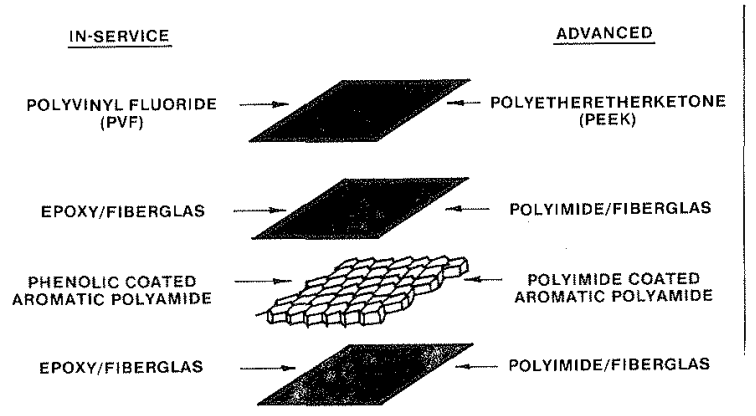

Figure 1. Composition of Composite Panels

The in-service panel contained epoxy/fiberglass facings and represented the type of panel design employed in the earliest wide-body jet interiors. polyimide was selected in the advanced panel design for resin and core coating because of its high degradation temperature. Polyetheretherketone (PEEK) was 
the decorative film in the advanced panel design, primarily to eliminate the production of hydrogen fluoride during thermal decomposition of the polyvinyl fluoride film commonly used in contemporary panels. The superior thermal. stability of the advanced panel was evidenced alone by its cure temperature; viz., $500^{\circ} \mathrm{F}$ for 16 hours vs. $350^{\circ} \mathrm{F}$ for approximately 2 hours for the inservice panel.

\section{Test Article}

The full-scale test article was a C-133 aircraft, modified to resemble a wide-body cabin interior, as shown in figure 2 and reference 2 . It was utilized to compare the performance of the advanced and in-service panels installed in a representative cabin interior layout as sidewalls, stowage bins, ceiling and partitions, under simulated postcrash and inflight fire conditions. Under the postcrash scenarios, the interior was subjected to an external fuel fire adjacent to an opening (door or fuselage rupture) in the forward part of the fuselage (figure 2). For the in-flight fire scenario, the fuselage openings were covered and a perforated ducting system simulated the ceiling discharge of air into the cabin as occurs with the cabin environmental control system (ECS).

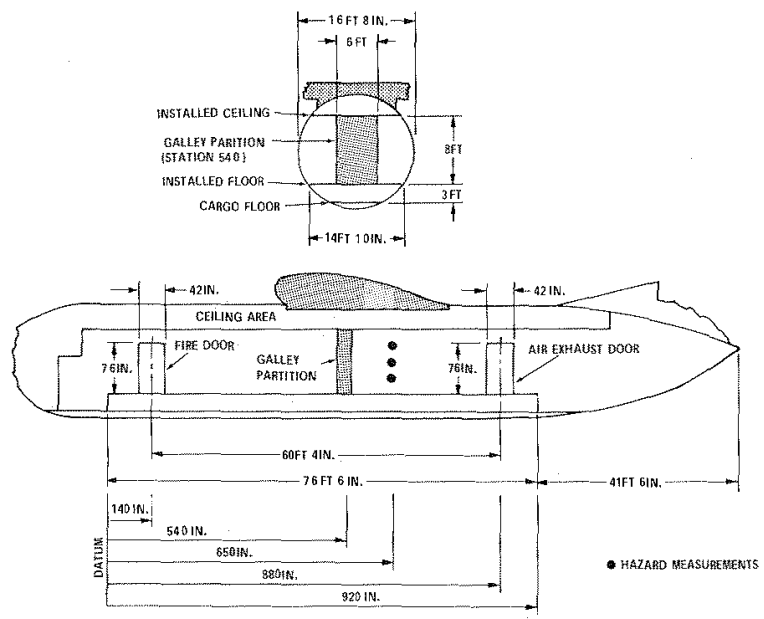

Figure 2. Schematic of C-133 Wide-Body Cabin Fire Test Article

Fire Scenarios

Table 1 outlines the fire scenarios utilized in this study. In the postcrash scenario, previous work had demonstrated that the size of the $C-133$ external fuel fire produced 80 percent of the radiant heat flux into the interior expected from an infinite fire. 7 Thus, the experimental fuel fire gave a reasonable simulation of a large pool of burning fuel. With an unfurnished c-133 interior and zero wind, there is virtually no accumulation of fuel fire hazards (temperature, smoke, and gases) inside the test article. 7 For this reason, the cabin hazards measured with interior materials installed and a zero wind fuel fire are attributed to burning materials, although fuel fire 
flames are drawn into the interior as the materials begin to ignite and burn. 8 The main role of the fuel fire is to subject the interior materials to intense radiant heat.

Table 1. Fire Scenarios

\begin{tabular}{|c|c|c|c|c|c|}
\hline No. & DESIGNATION & TYPE & $\begin{array}{l}\text { IGNITION } \\
\text { SOURCE }\end{array}$ & $\begin{array}{c}\text { FUSELAGE } \\
\text { CONFIGURATION }\end{array}$ & VENTILATION \\
\hline 1 & $\begin{array}{l}\text { FUEL FIRE/ } \\
\text { RUPTURE }\end{array}$ & POSTCRASH & FUEL FIRE & $\begin{array}{c}\text { INTACT, TWO } \\
\text { OPENINGS: } \\
\text { RUPTURE (FIRE) } \\
\text { DOOR (AFT) }\end{array}$ & $\begin{array}{l}\text { NATURAL } \\
\text { ZERO WIND }\end{array}$ \\
\hline 2 & $\begin{array}{l}\text { FUEL FIRE/ } \\
\text { OPEN DOOR }\end{array}$ & POSTCRASH & FUEL FIRE & $\begin{array}{l}\text { INTACT, TWO } \\
\text { OPENINGS: } \\
\text { DOOR (FIRE) } \\
\text { DOOR (AFT) }\end{array}$ & $\begin{array}{l}\text { NATURAL } \\
\text { ZERO WIND }\end{array}$ \\
\hline 3 & $\begin{array}{l}\text { GASOLINE/ } \\
\text { SEAT }\end{array}$ & IN-FLIGHT & $\begin{array}{c}\text { SPILLED } \\
\text { GASOLINE } \\
\text { ON SEAT }\end{array}$ & CLOSED & CONTROLLED \\
\hline
\end{tabular}

The in-flight fire scenario consisted of the ignition of a passenger seat doused with one quart of gasoline. It probably represented the most intense in-flight fire that is likely to occur out in the open (in contrast to a fire in a concealed area). The use of forced ventilation in a closed fuselage for the in-flight scenario was expected to affect the fire characteristics, compared to the postcrash case with fuselage openings and natural ventilation.

\section{TEST RESULTS AND ANALYSIS}

Postcrash Fuel Fire and Fuselage Rupture Scenario

The arrangement of materials with the postcrash fire scenario with a fuselage rupture adjacent to the fuel fire is shown in figure 3. Basically, a small area of the interior in the vicinity of the fuselage rupture was lined with the panels being examined and furnished with seats and carpet. The seats were surplus aircraft passenger seats protected with cushion fire blocking layers and the carpet was new, aircraft grade wool/nylon carpet. The quantity of materials employed was more than adequate to produce non-survivable conditions in the event of ignition and adequate fire growth. By using seats and carpet in addition to the panels being evaluated, the effect of panel flammability on the ignition and burning of other cabin materials used in large quantities, and vice-versa, was taken into consideration.

GEILING, STOWAGE BIN AND SIDEWAL. MATERIAL

TWOAPET MATERIAL

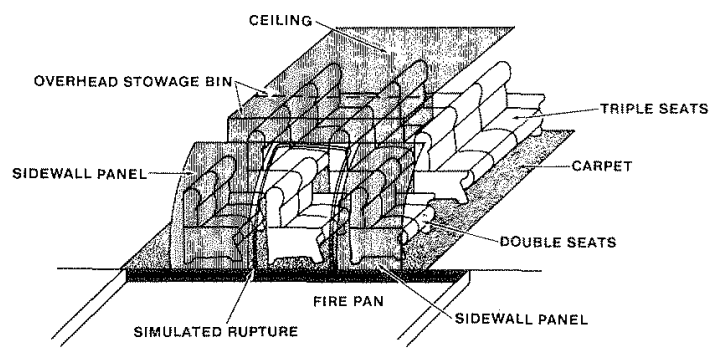

Figure 3. Postcrash Fuel Fire/Rupture Scenario 
The postcrash fuel fire scenario with a fuselage rupture was the most severe fire condition used, primarily because a seat was centered in the rupture and exposed to high levels of radiant heat. A flashover - defined in this paper as the sudden and rapid uncontrolled growth of the fire from an area in the immediate vicinity of the fuel fire to the remaining materials - occurred with both types of panels. However, the time to flashover was much earlier in the test with in-service panels than in the test with advanced panels. As shown in figure 4, the difference in flashover times was approximately 140 seconds. Since the occurrence of flashover is the event in a postcrash cabin fire that creates nonsurvivable conditions, as discussed later in this paper and in an earlier study (reference 2), the advanced panels also resulted in 140 seconds of additional time available for evacuation. This difference in available evacuation time was clearly a significant benefit to be gained from the advanced panels.

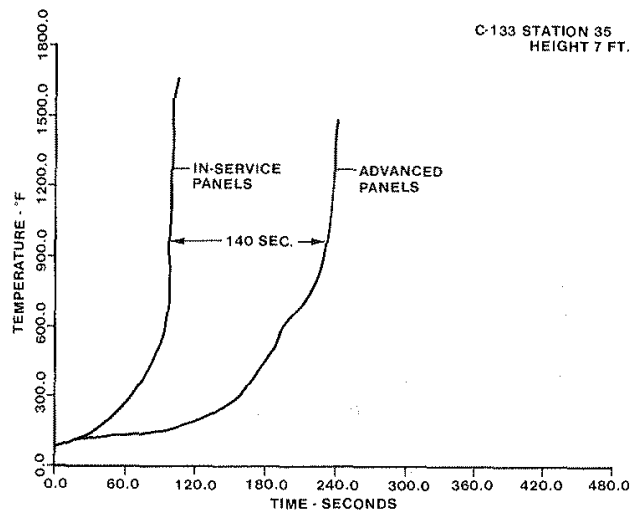

Figure 4. Benefit of Advanced Composite Panels-External Fuel/Fuselage Rupture Scenario

Postcrash Fuel Fire and Open Door Scenario

The arrangement of materials with the postcrash fire scenario with an opened door adjacent to the fuel fire was similar to the fuselage rupture scenario except that the center row of seats was eliminated and a box-1ike structure representing a galley was installed. The resultant fire condition was less severe than with the fuselage rupture scenario because of the removal of the passenger seat next to the opening.

The superior fire performance of the advanced panels was even more evident with the fuel fire/open door scenario. Under this scenario, the usage of advanced panels eliminated flashover. This result is demonstrated in figure 5, which compares the temperature history inside the test article for both types of panels. With in-service panels, flashover occurred in aproximately 2 $1 / 2$. minutes; however, with advanced panels, flashover did not occur over the 7-minute test duration. A comparison of the results with both types of postcrash scenarios (see figures 4 and 5 ) demonstrates the consistency of the data and illustrates that the rate of development of a cabin fire is largely dependent on fire scenario. 


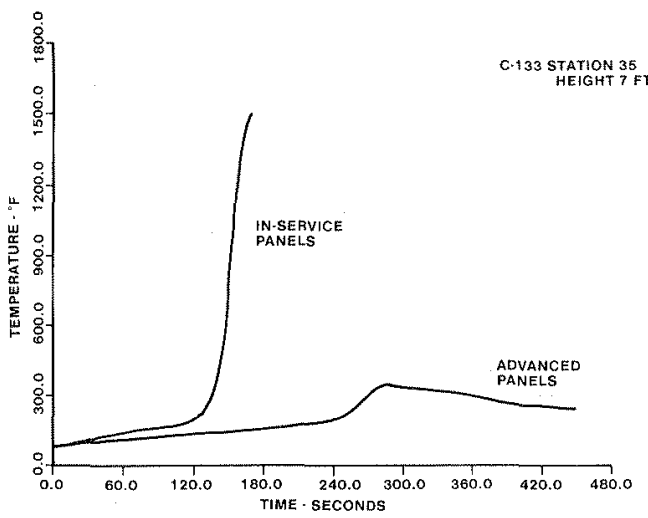

Figure 5. Benefit of Advanced Composite - External Fuel Fire/Open Door Scenario

An analysis of the cabin hazards measured in the fuel fire/open door test with in-service panels revealed the importance of flashover in dictating survivability during a postcrash cabin fire. This data is shown in figure 6 , which contains the hazard histories measured approximately 40 feet aft of the fire door at an elevation of 5 feet 6 inches. Before the flashover which occurred at approximately 150 seconds, the cabin environment was clearly survivable; after flashover, the conditions very suddenly deteriorated to such a degree that survival would have been highly unlikely. The suddeness of flashover, and perhaps the fact that it occurs without any apparent warning, may make passengers unaware of the imminent dangers that they face during a cabin fire. For example, within 30 seconds, as shown in figure 6 , visibility decreased from about 30 feet to 3 feet, temperature measured from slightly above ambient to over $400^{\circ} \mathrm{F}, \mathrm{CO}$ increased from zero to over $2500 \mathrm{ppm}$, and oxygen decreased from ambient to 16 percent. Therefore, it was concluded that improvements in postcrash cabin fire safety, when burning interior materials are the dominant factor, can be best attained by delaying the onset of flashover. If material selection is on the basis of state-of-the-art small-scale fire tests, then the use of an appropriate flammability test would seem to be far more beneficial than the use of either smoke or toxicity tests.

Why were the hazards measured 40 feet aft of the fire door at an elevation of 5 feet 6 inches virtually zero for over 2 minutes in the fuel fire/open door test with in-service panels? There are two likely reasons for this result.

First, the small mass burning rate before flashover and the large cabin volume $(13,200$ cubic feet) made dilution and wall loss effects (heat transfer, adsorption) dominant. Secondly, the hazards that are produced before flashover are largely contained in the hot "smoke layer" which clings to the ceiling, above the measurement location and probably above the head of most passengers. Previous $\mathrm{C}-133$ tests 2 , and the photographic/ video coverage from the tests described in this paper, document the significant stratification during a postcrash cabin fire with natural ventilation; i,e., with no. forced ventilation. 
The in-flight fire scenario was the least severe of the three scenarios studied. Figure 8 compares the temperature history near the fire source for the in-service and advanced panels. As in the fuel fire/open door test, flashover did not occur with the advanced panels. The fire resistance of the more flammable in-service panels was also sufficient to delay the onset of flashover until 8 minutes. From a practical viewpoint, an in-flight fire of this kind with inservice panels would, under most circumstances, have been extinguished by crewmembers utilizing hand-held extinguishers before the fire became out ot control.

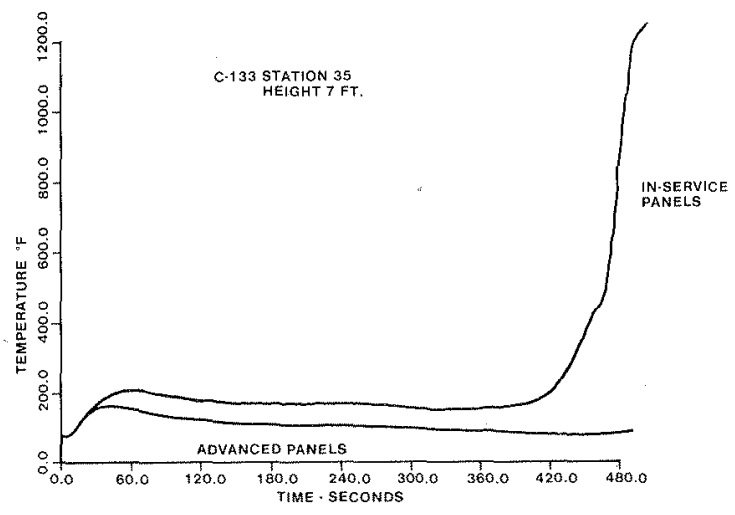

Figure 8. Benefit of Advanced Composite Panels - In-Elight Fire Scenario

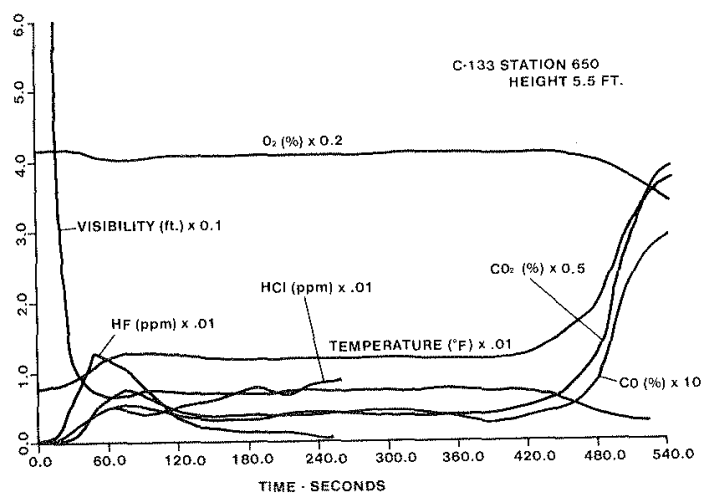

Figure 9. Hazard Time Profiles With In-Service Composite Panels - Flight Fire Scenario

The controlled ventilation in the in-flight scenario tended to distribute the seat fire hazards throughout the airplane. Figure 9 presents the measured hazard histories for the in-service panel test. Each of the measured hazards was detected before the onset of flashover, apparently because of the mixing action associated with the controlled ventilation. In contrast, for the postcrash tests where the cabin was ventilated naturally through fuselage openings, the hazards were primarily contained in the ceiling smoke layer, and remained virtually undetected at the 5-foot 6-inch sampling height until the 


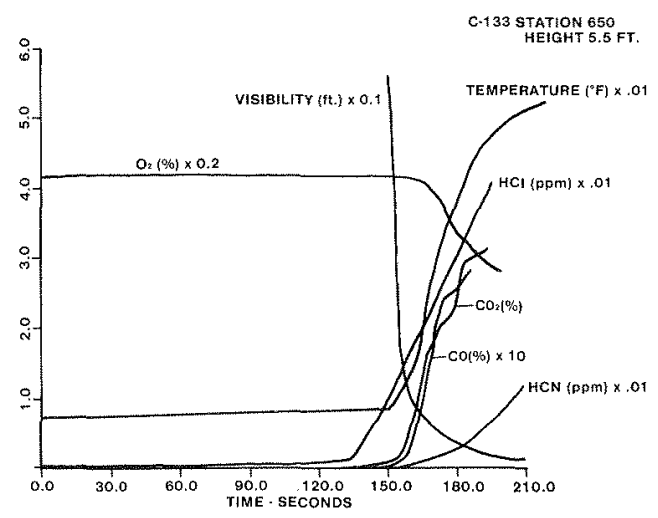

Figure 6. Hazard Time Profiles with In-Service Composite Panel - External Fuel Fire/Open Door Scenario

Figure 7 also demonstrates that the hazards over this 7 -minute test were clearly survivable. At 7 minutes, the temperature had only increased by $20^{\circ} \mathrm{F}$ over ambient, the concentration of $\mathrm{CO}_{2}$ was $2000 \mathrm{ppm}$, the concentration of $\mathrm{O}_{2}$ remained at ambient, and visibility had decreased to 50 feet. The toxic gases $\mathrm{CO}, \mathrm{HCl}$, HCN, and HF were not detected. This data also supports the conclusion that in a postcrash cabin fire, the hazards effecting survival are created by a flashover. Also, smoke and toxic gas hazards affecting survivability did not materialize as a consequence of flashover being prevented.

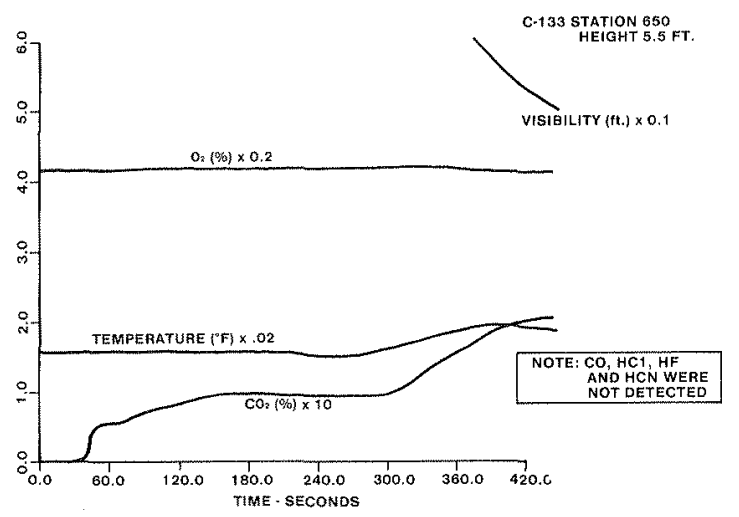

Figure 7. Hazard Time Profiles With Advanced Composite Panels External Fuel Fire/Open Door Scenario

\section{In-Flight Fire Scenario}

For the in-flight scenario, the fuselage openings were covered and a perforam ted duct simulated air discharge from the cabin ECS. The seat next to the covered door, doused with one quart of gasoline, served as the fire source. This type of seat fire will burn for 2 mnutes, with a peak burning rate at 40 seconds before self-extinguishing because of the fire blocking layer. 9 
cabin flashover (e.g., see figure 6). For the in-flight test, however, each measured hazard before flashover was well below its estimated incapacitation leve1. For example, at 8 minutes the calculated dose of $C O$ was approximately 4000 ppm-minutes, which is significantly below the estimated human escape impairment dose of 30,000-40,000 ppm-minutes. 10 Also, the measured concentration of $\mathrm{HCl}$, which was less than $100 \mathrm{ppm}$, would have been easily tolerated by passengers, based on recent primate studies. 10 The main peril before flashover was the dramatic loss in visibility due to smoke (calculated visibility was less than 10 feet at 30 seconds). It is interesting to note that significant smoke obscuration can occur without hazardous levels of toxic gases or elevated temperatures.

\section{SUMMARY OF SIGNIFICANT FINDINGS}

Based on the realistic, full-scale cabin fire tests and analysis described in this paper, and on the composite panel materials evaluated and the types of fire scenarios employed, the following are the significant findings:

1. Advanced interior panels can provide a significant safety improvement during postcrash and in-flight cabin fires.

2. The greatest threat to passenger survival during postcrash cabin fires dominated by burning interior materials, is cabin flashover.

3. Toxic gases produced during postcrash $c a b i n$ fires consisting of a fuel fire adjacent to a fuselage opening or in-flight fires initiated by a gasoline-drenched seat fire do not reach hazardous levels unless flashover occurs.

4. During an in-flight fire, the cabin environmental control system has a major effect on the distribution and dissipation of hazards.

\section{REFERENCES}

1. Final Report of the Special Aviation Fire and Explosion Reduction (SAFER) Advisory Committee, Federal Aviation Administration, Volume I, Report FAA-ASF80-4, June 26,1980 .

2. Sarkos, C. P., Hil1, R. G., and Howe11, W. D., The Development and Application of a Fu11-Scale Wide-Body Test Article to Study the Behavior of Interior Materials During a Postcrash Fuel Fire, AGARD Lecture Series No. 123 on Aircraft Fire Safety, AGARD-LS-123, June 1982.

3. Engineering and Development Program Plan Aircraft Cabin Fire Safety, Federal Aviation Administration, Report FAA-ED-18-7, revised February 1983.

4. Aircraft Accident Report: Air Canada Flight 797, McDone11-Douglas DC-9-32, C-FTLU, Greater Cincinnati International Airport, Covington, KY, June 2, 1983 , $\mathrm{N}$ at ional Transport ation Safety Board, Report NTSB/AAR-84/09, August 8, 1984

5. Sarkos, C. P., and Hill, R. G., Effectiveness of Seat Cushion Blocking Layer Materials Against Cabin Fires, SAE Technical Paper No. 821484, presentd at Aerospace Congress and Exposition, October 25-28, 1982.

6. Flammability Requirements for Aircraft Seat Cushions; Notice of Proposed Rulemaking, DOT/FAA, Federal Register, Volume 48, No. 197, p. 46251, October 11,1983 . 
7. Hill, R. G., Johnson, G. R., and Sarkos, C. P., Postcrash Fuel Fire Hazard Measurements in a Wide-Body Aircraft Cabin, Federal Aviation Administration, Report FAA-NA-79-42, December 1979.

8. Quintiere, J. G., and Tanaka, T, An Assessment of Correlations Between Laboratory and Ful1-Scale Experiments for the FAA Aircraft Fire Safety

Program, Part 5: Some Analyses of the Postcrash Fire Scenario, National Bureau of Standards, Report NBSIR 82-2537, July 1982.

9. Hill, R. G., Brown, L. J., Speitel, L., Johnson, G. R., and Sarkos, C. P., Aircraft Seat Fire Blocking Layers: Effectiveness and Benefits Under

Various Scenarios, Federal Aviation Administration, Report DOT/FAA/Cr $-83 / 43$, February 1984 .

10. Kaplan, H. L., Grand, A. F., Rogers, W. R., Switzer, W. G., and Hartze11, G. E., A Research Study of the Assessment of Escape Impairment by Irritant Combustion Gases in Postcrash Aircraft Fires, Federal Aviation Administration, Report DOT/FAA/ CT-84/16, September 1984. 